DOI: 10.20472/IAC.2018.044.045

\author{
LILACH SHALIT \\ Kibbutzim College of Education, Technology and the Arts , Israel \\ TALI RONEN \\ Kibbutzim College of Education, Technology and the Arts , Israel
}

\title{
DEVELOPING LEARNING SKILLS THROUGH MOVEMENT
}

\begin{abstract}
:
Physical movement, in addition to its importance in motor development, may also contribute to academic learning and to the improvement of cognitive skills.

This lecture focuses on two research studies which examine the effect of physical exercise and body movement activities on different populations. Both studies used the movement and structural principles of Eshkol-Wachman Movement Notation (EWMN).

EWMN is a language based on an analytical method that defines the essential units required for the description of bodily movement in time and space.

The first research examined an intervention program consisting of a combination of movement by means of EWMN and academic learning. The aim of the program was to improve the achievements of 3rd and 4th grade pupils in learning an academic subject as they studied two topics in geometry: angles and symmetry. The study compared two experiment groups with two control groups. This was Mixed Methods Research which made use of three research tools. The findings of the study clearly show that the achievements of the pupils who participated in the experimental groups were higher than those of the pupils who participated in the control groups.

The second research study examined the effect of movement and coordination exercises, based on EWMN, on students who have Attention Deficit Hyperactivity Disorder (ADHD). The study examined a movement intervention program of thirteen weeks duration in two different but related fields of knowledge: attention, a cognitive skill, and coordination, a physical skill. This population was chosen because earlier studies have shown that physical exercise is likely to have a positive effect on people with ADHD. The findings of the study show that the students improved their results according to the attention and coordination tests that were administered.
\end{abstract}

\section{Keywords:}

Coordination, Theoretical Movement Learning, Eshkol-Wachman Movement Notation 